\title{
Thermal Characterization of Resin Concrete Elaborate By Infusion
}

\section{I.Hawachi"' H.Sammouda*}

*Laboratory of Energy and Material (LabEM-LR11ES34) University of Sousse- Tunisia, ESSTHS, Rue Lamine Abbassi, 4011, Hammam Sousse, Tunisia

\begin{abstract}
This paper presents the results of numerical simulation to investigate the effect of temperature on the performance of resin concrete. Resin concrete is a composite material in which polymeric materials are used to bond the aggregates in a fashion similar to that used in the preparation of cement concrete. In this paper, at first the temperature distribution in gravel preform heated with epoxy resin injection was investigated. Furthermore, a thermo-mechanical study is presented. For this purpose, prismatic and cylindrical specimens were prepared for flexural and compressive tests, respectively, at different temperatures. The effect of heating on the thermal conductivity and elastic modulus were evaluated.

Finally, the thermal behavior of resin concrete has been compared to that of cement concrete. When exposed to high temperatures the epoxy polymer concrete shows a significant loss of strengths mainly due to the thermo-oxidative degradation of the epoxy polymer and to the debonding between aggregates and the binder. Results show that when exposed to temperatures less than $250^{\circ} \mathrm{C}$ the epoxy polymer concrete is still more efficient than cement based concrete.
\end{abstract}

Keywords: Resin concrete; Material behavior; High Temperature; Numerical simulation.

\section{Introduction}

A considerable amount of research has been performed on the thermal degradation of polymer matrix composites because this is a major problem in the application of thermoset polymers in different types of environments that are subjected to temperature changes.

The composite material behavior under different temperatures is an important parameter to be considered because it can, in many cases, determine the upper bound on the temperatures at which a material has suitable properties. The objective of this work is the development of a thermomechanical model capable of simulating the high-temperature behavior of polymer concrete while solving the non-linear EDP system using the Comsol calculation code[1].

The polymer concrete is one of the youngest building materials, and they are continually appearing with new and optimized properties as new combinations and formulations are developed, regardless of their significant advantages in comparison with conventional construction materials.

However, the main problem with polymeric materials arises from the viscoelastic properties of the polymer, which result in creep and a high sensitivity to temperature. The effects of temperature on the mechanical properties of polymers change considerably, especially within the heat distortion temperature range.

In this study, polymer concrete is tested under different temperatures to evaluate their behavior when they are subjected to flexure and compression. A polymer concrete (PC) is a composite material in which polymeric materials, thermoset resins, are used to bond the aggregates in a fashion similar to that of cement with some aggregates mixed in it and make a hard paste that is called cement concrete.

Various studies are interested in the behavior of concretes subjected to high temperature. It is found that under certain conditions, studies have been conducted to explain bursting of concrete brought to a high temperature. [2-4].In other studies [5-7] they have simulated the behavior of this concrete at high temperature in an attempt to explain the mechanisms. 
The studies of Reis [8] present the results of an experimental program to investigate the effect of temperature on the performance of epoxy and unsaturated polyester polymer mortars (PM). PM is a composite material in which polymeric materials are used to bond the aggregates in a fashion similar to that used in the preparation of Portland cement concrete.

Measurements of the temperature-dependent elastic modulus and the compressive and flexural strength were conducted using a thermostatic chamber attached to a universal test machine for a range of temperatures varying from room temperature to $90{ }^{\circ} \mathrm{C}$. The flexural and compressive strength decreases as temperature increases. Epoxy polymer mortars are more sensitive to temperature variation than unsaturated polyester ones.

Some studies have been done on the thermal degradation of polymer matrix composite materials. Indeed this major problem is encountered in the application of thermosetting polymers in different types of environmental elements that are subject to temperature changes [9].

However, the main problem with polymeric materials arises from the viscoelastic properties of the polymer, which result and a high sensitivity to temperature [10-13]. The effects of temperature on the mechanical properties of polymers change considerably, especially within the heat distortion temperature range lies between 20 and $80{ }^{\circ} \mathrm{C}$ [14].

In a study complementary to that of Abdel-Fattah and El-Hawary [15-16] formulated BRs which are stressed in compression and tensile strength for temperatures ranging from 20 to $200^{\circ} \mathrm{C}$. They conclude that the mechanical properties of these resinous concretes vary according to the type of resin used and that these characteristics in addition to rigidity generally increase with the temperature of exposure.

Vipulanandran el al. [17-18] found that the effect of temperature on the mechanical properties in bending of the optimum BR up to $110^{\circ} \mathrm{C}$ and that these properties (resistances, behavior, rigidity) are more sensitive to the exposure to medium temperatures than those to compression. This maximum temperature $\left(110^{\circ} \mathrm{C}\right.$. $)$ is chosen on the basis of the glass transition temperature (between 125 and $150{ }^{\circ} \mathrm{C}$.) of the BRs and the samples are exposed for 3 hours.

The study of the effect of temperature on the mechanical behavior of resin concretes is of crucial importance. This is explained by the fact that these materials are exposed to thermal stresses that can cause the rupture of the resin matrix, especially in southern countries where the number of sunny hours is very important.

\section{Modeling}

The objective is to simulate a thermal loading on a concrete specimen and to observe its behavior ac-cording to whether we consider homogeneous properties with one phase only: all the finite elements have the same thermo-mechanical properties.

A classic thermo-mechanical approach is used for numerical resolution:

- The heat equation (energy balance equation) is used to compute the temperature evolution;

- An elastic damage model is used for concrete and cement paste [19] to predict cracking evolution during heating, and an elastic model is used for aggregates (due to the lack of experimental data).

\subsection{Thermal Transfer During The Infusion Process}

The resin infusion process (RIP) has been developed as an inexpensive method for the manufacture of large fiber reinforced materials. In this paper, we show the implementation of $2 \mathrm{D}$ numerical models to study the heat transfer during the infusion process.

The results show that the model developed is very applicable for the manufacture of composite materials. The objective of this study is to test the model developed for later use in a real application.

The aim of this study is to develop a global solver to simulate the resin flow in a porous body. The new model concept can be used to describe transfer in a porous medium, and it is based on existing approaches and valid on the representative elementary volume (REV) scale [20].

The thermal problem in the solid and in the fluid is thus approached in order to facilitate the understanding of the phenomena studied in the coupling: conduction in the solid, conduction and convection in the fluid. The coupling between fluid and solid is played at their interface. The boundary conditions will therefore have an essential role and will then be subject to certain investigations. 
Choosing the proper constitutive laws is one of the key issues when it comes to solve the fluid flow of a material. In our case, the constitutive law is given by Darcy's law [21].

The model studied in this part is composed of two domains, the first of which is filled with the resin and the second is a porous medium formed by aggregates where the resin is injected by the LRI [ 22 ] process consists of using highly permeable drainant. This is placed above the fiber preforms. In fact, a pressure differential applied between the resin inlet, located at the level of the drainant, and the base of the preform, causes the resin to infuse inside the drainant and then through the thickness of the preforms. When the infusion is finished, a pressure and temperature cycle is applied so that the crosslinking of the resin takes place (Fig.1).

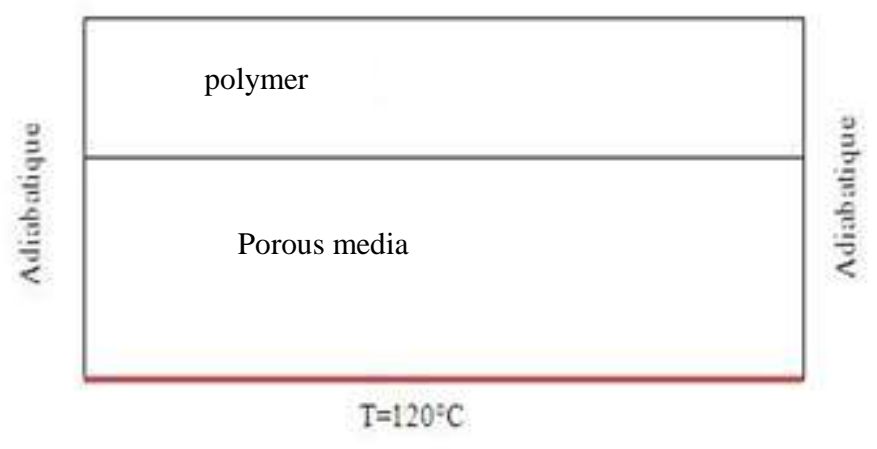

Fig.1. Physical model of temperature transfer during the infusion process

\section{- Transfer within the porous medium}

The heat transfer model most used for porous media [23]:

$(\rho C)_{e} \frac{\partial T}{\partial t}+(\rho C)_{f} \vec{V}_{f} \cdot \vec{\nabla} T=\operatorname{div}[k \vec{\nabla} T]$

With $\mathrm{T}$ the equivalent temperature of the porous medium, $(\rho C)_{e}=\phi(\rho C)_{f}+(1-\phi)(\rho C)_{s}$ the equivalent volume specific heat, $k=\phi k_{f}+(1-\phi) k_{s}$ the equivalent thermal conductivity and is the rate of filtration.

\section{- Transfer within the polymer}

The heat transfer within a liquid polymer is written [23]:

$$
\rho_{p} C_{p p} \frac{\partial T}{\partial t}+\operatorname{div}\left(\rho_{p} C_{p p} T \vec{V}-k_{p} \vec{\nabla} T\right)=f
$$

- Numerical simulation of the thermal behavior during the infusion process:

In this part we will study the evolution of the temperature of the preform during the infusion process. The problem of the thermal in the solid and in the fluid is thus approached in order to facilitate the understanding of the phenomena studied in the coupling: the conduction in the solid, the conduction and the convection in the fluid. The coupling between fluid and solid is played at their interface. The boundary conditions will therefore have an essential role and will then be the subject of certain investigations.

For the preparation, there are two different conditions: either the preform is placed on a hot plate [24], or the preform is put in a glass oven [25].

The preform dimensions are given in the table. Resin is preheated to $80^{\circ} \mathrm{C}$ before infusion. A heating plate located below the preform heats the whole infusion system. The external pressure prescribed over the stacking is uniform and equal to the local atmospheric pressure.

\begin{tabular}{|l|l|l|}
\hline & width & height \\
\hline
\end{tabular}




\begin{tabular}{|l|l|l|}
\hline resin & $4 \mathrm{~cm}$ & $2 \mathrm{~mm}$ \\
\hline $\begin{array}{l}\text { porous } \\
\text { medium }\end{array}$ & $4 \mathrm{~cm}$ & $1 \mathrm{~cm}$ \\
\hline
\end{tabular}

Table1. Size of the model

Initial conditions and limits

- Lower edge subjected to temperature $\mathrm{T}=120^{\circ} \mathrm{C}$ which corresponds to that of the heating plate is at $120^{\circ}$ C.

- Upper edge $\mathrm{T}=20^{\circ} \mathrm{C}$

- the side walls are adiabatic

- The initial temperature of the resin T0r $=80^{\circ} \mathrm{C}$.

- The temperature of the initial of the porous medium $\mathrm{T} 0 \mathrm{p}=20^{\circ} \mathrm{C}$.

The materials chosen for this example are a resin matrix and a sand reinforcement. Thanks to their properties, it is possible to determine that of the composite formed.

\begin{tabular}{|l|c|l|l|}
\hline & $\begin{array}{c}\text { Volumic } \\
\text { mass } \\
{\left[\mathrm{Kg} / \mathrm{m}^{\wedge} 3\right]}\end{array}$ & $\begin{array}{l}\text { Heat } \\
\text { capacity } \\
\mathrm{Cp} \\
{\left[\mathrm{J} \cdot \mathrm{kg}^{-1} \cdot \mathrm{K}^{-1}\right]}\end{array}$ & $\begin{array}{l}\text { Thermal } \\
\text { conductivity } \\
\left.\mathrm{k} . \mathrm{m}^{-1} \cdot \mathrm{K}^{-1}\right]\end{array}$ \\
\hline resin & 938 & 1950 & 0.25 \\
\hline sand & 1417 & 835 & 0.33 \\
\hline
\end{tabular}

Table 2.Properties of composites

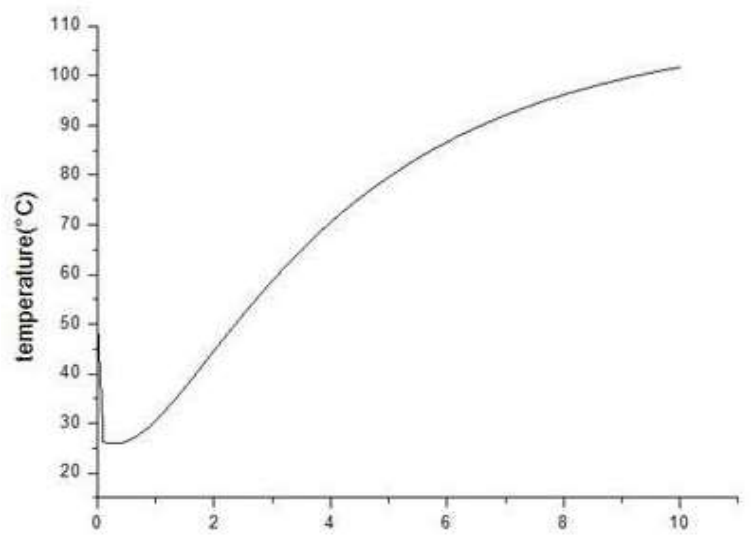

$\mathrm{t}(\mathrm{s})$

Fig.2. Variation of the temperature in the material during the infusion process $(x=6 \mathrm{~cm}, y=-0.01 \mathrm{~cm})$.

The temperature during the infusion stage tends to decrease when the test begins and that the resin is left free to fill in the preform. This phenomenon confirms the presence of resin that tends to cool down the preform, after this minimum is reached, the temperatures of the thermocouples increase, because the resin temperature continues increasing while it flows into the preform.

Figure 3 shows the variation of the temperature in the depth of the preform over time. It is found that the temperature increases in the porous medium since more than the resin occupies the pores and arrives after a certain time in contact with the hot plate and it will be heated by conduction. Eventually the saturated preforms reach a stabilized temperature, which is related to the filling duration of the infusion stage 


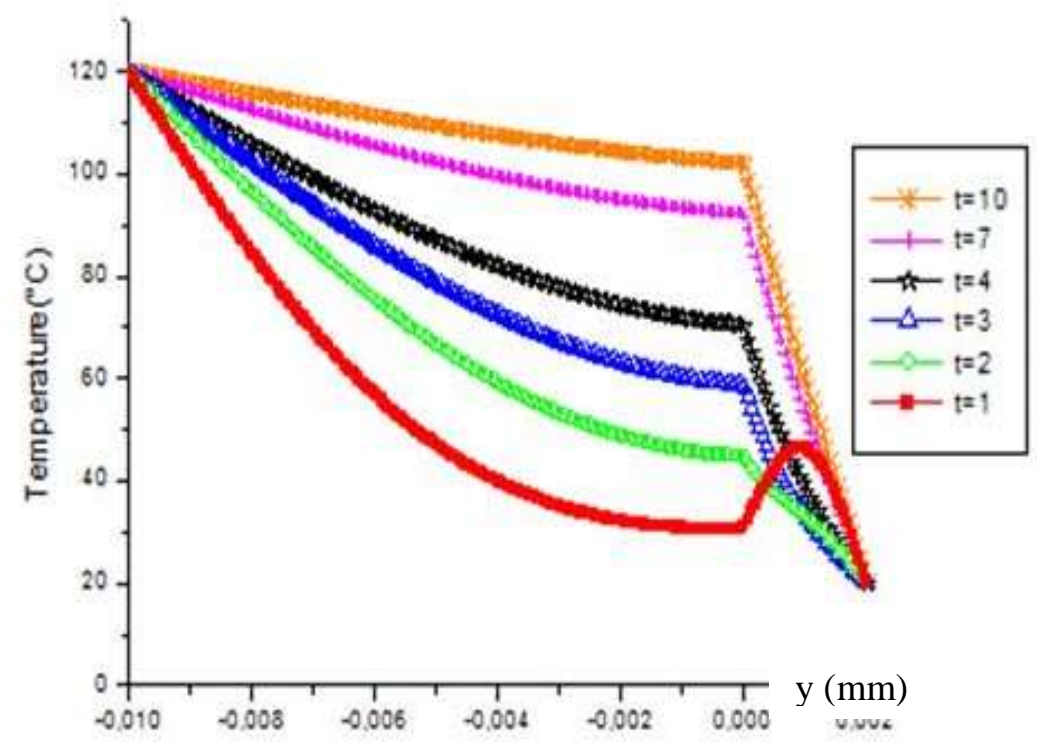

Fig.3. Variation of the temperature during the infusion process for different time $(\mathrm{t}(\mathrm{s}))$

\subsection{Thermo-mechanical behavior of resin concrete}

In this section we will develop a numerical model to study the behavior of flat structures in polymer concrete under two mechanical and thermal loadings.

Thermal cycling involves repeatedly cycling a specimen or material between two temperatures to allow thermal equilibrium to be attained. It is assumed that the heating rate is not fast enough to induce thermal shock.

To investigate the effects of the thermal cycles on the compressive and bending of the PC, two specimens are used according to dimensions in Fig 4 and exposed to the a thermal cycle, as follows. Thermal cycling involves repeatedly cycling a specimen or material between two temperatures at either extreme to allow thermal equilibrium to be attained.

- Flexural cycle: $25^{\circ} \mathrm{C}$ to $-30^{\circ} \mathrm{C}$

- Compressive cycle: 25 to $80^{\circ} \mathrm{C}$

\section{- Flexural test}

Polymer concrete is a composite material in which polymeric materials are used to bond the aggregates in a fashion similar to that used in the preparation of Portland cement concrete. For this purpose, prismatic and cylindrical specimens were prepared for flexural and compressive tests, respectively, at different temperatures.

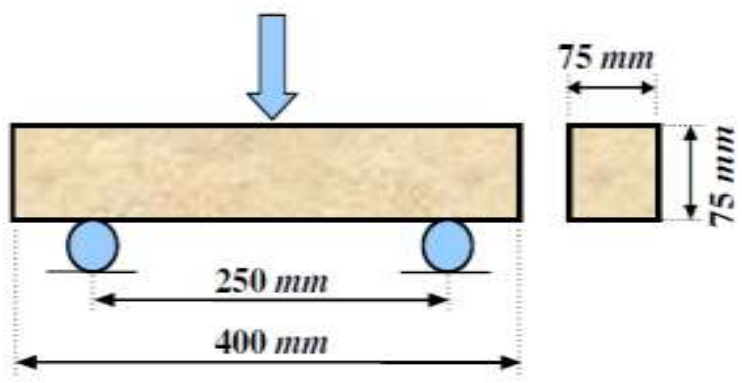

Fig.4. Flexural Test

The material studied was prepared by mixing sand with the epoxy resin binder by adding glass fibers. According to Shokrieh's experience [26] the sample is exposed to a thermal cycle in the following way: $25^{\circ}$ $\mathrm{C}$ to $-30^{\circ} \mathrm{C}$ or the thermal cycles are carried out by a thermal chamber.

Three-point bending test was performed. Bending test setup, of the PC specimen exposure to the thermal cycles are shown in Fig. 5. In the flexural test, it is observed that applied load suddenly decreases at failure. 
The load deflection that the force varies linearly with respect to the deflection of the middle point of the beam in a wide range of loading.

In the flexural test, the load-displacement curve varies linearly and after maximum applied load, it decreases by a soft slope.

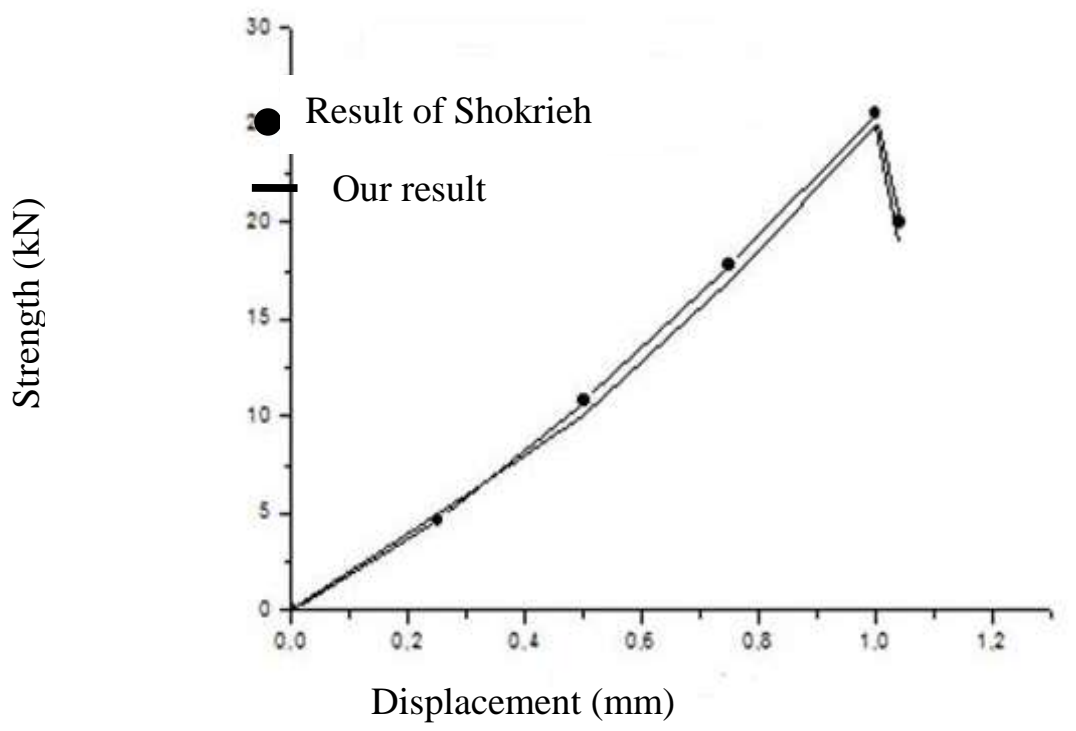

Fig.5.Comparison of our work and the work of Shokrieh [26] for a test case of bending subjected to a thermal load of $25^{\circ} \mathrm{C}$ to $-30^{\circ} \mathrm{C}$.

\section{- Compressive test}

The material used for this case was prepared by mixing foundry sand with the thermoset resin binder. A mechanical test is performed on the proposed PC. Compressive test is done with $5 \mathrm{~mm} / \mathrm{min}$ crosshead velocity. Specimen is in form of the cylinders with $50 \mathrm{~mm}$ diameter and $100 \mathrm{~mm}$ height.

To determine the influence of temperature on the mechanical strength of the PC, compressive test is performed at different temperature levels. The test temperatures range from room temperature to $80{ }^{\circ} \mathrm{C}$.

The conditions of the experiment were: The density of the sand is $2650[\mathrm{~kg} / \mathrm{m} \mathrm{3}$ ], the resin content was $12 \%$ by weight and $88 \%$ of the aggregates of particles for complete formulations of the material.

Table 3 Mechanical and thermal properties of the epoxy resin [27]

\begin{tabular}{|l|l|}
\hline property & Epoxy resin \\
\hline Viscosity $(\mathrm{cP})$ at $25^{\circ} \mathrm{C}$ & 1450 \\
\hline Density $\left(\mathrm{kg} / \mathrm{m}^{\wedge} 3\right)$ & 1100 \\
\hline Deformation temperature $\left({ }^{\circ} \mathrm{C}\right)$ & 63 \\
\hline Modulus of elasticity $(\mathrm{GPa})$ & 3.5 \\
\hline
\end{tabular}

Fig. 6 shows Compressive test setup of a specimen exposed to the thermal cycles $\left(20^{\circ} \mathrm{C}\right.$ to $\left.80^{\circ} \mathrm{C}\right)$.

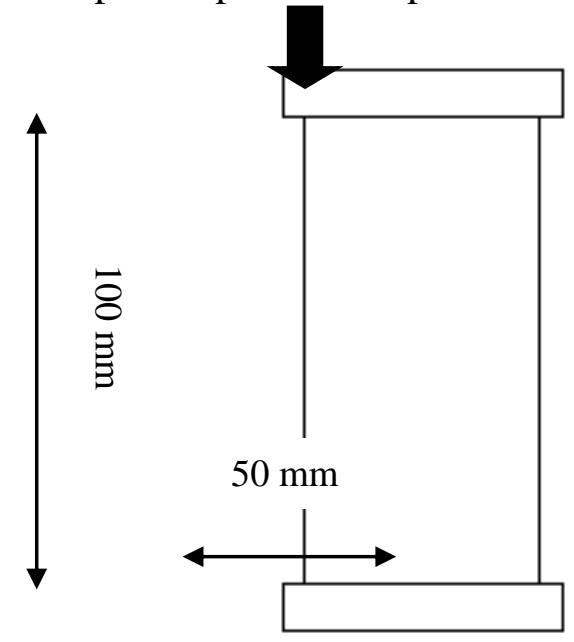

Fig.6. Compressive test 
Fig.7 shows the load-displacement curve of the compressive specimen exposed to the thermal cycles.

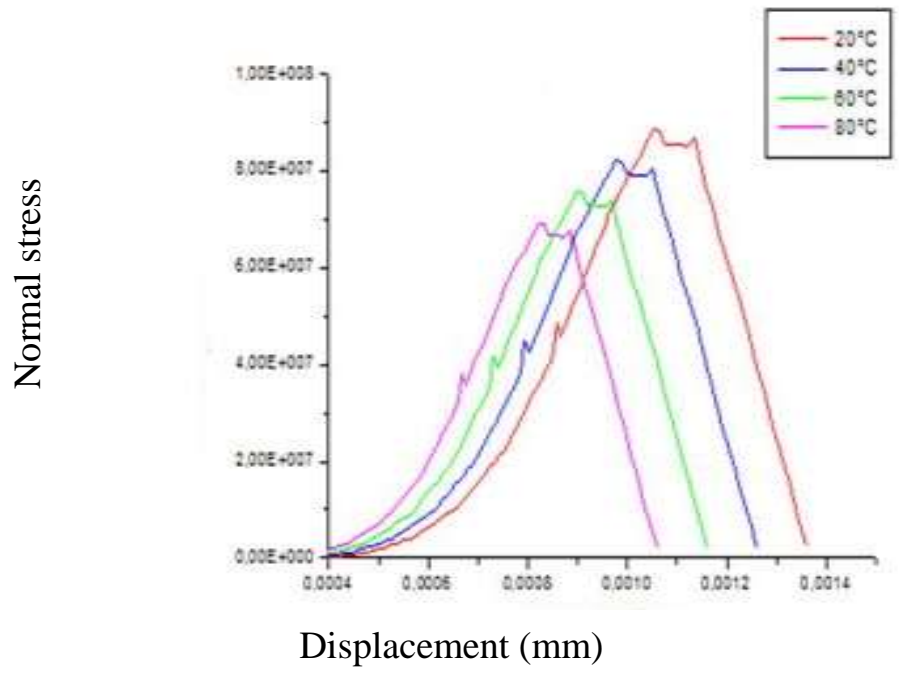

Fig.7. Compressive behavior of the PC at different test temperatures.

Figure 7 allows us to evaluate the compressive stress-strain behavior and to follow the phenomena that occur during temperature increase.

According to Fig.7, losses in the compressive stress of the epoxy mortar are reported from $40{ }^{\circ} \mathrm{C}$ to $90{ }^{\circ} \mathrm{C}$. We observe that the compressive stress at $90{ }^{\circ} \mathrm{C}$ is the lowest reported. As the test temperature increases, the compressive elasticity modulus decreases, and failure becomes less brittle.

\section{Comparison Between Heat Transfer In Resin Concrete And Cement Concrete}

After having validated our model, we are interested in the real problem to determine the properties of resin concrete and to compare it with those of cement concrete widely used in the country exposed to the sun.

Polymer concretes (PC) were introduced to building and construction industry more than 50 years ago [28]. Gradually, they became a suitable substitute for concrete structures; however, their application was shortly diminished due to the higher costs. In this research a homemade cost-quality effective resin (unsaturated polyester) is used as binder in the polymer concrete production. A model of dimension $\left(120 \times 120 \mathrm{~mm}^{2}\right)$ is presented for evaluated the thermal test. A comparative study was performed on the polymer concrete specimen, the ordinary cement concrete (normal concrete). It was found that the PC material show much better thermal properties than the durable concrete.

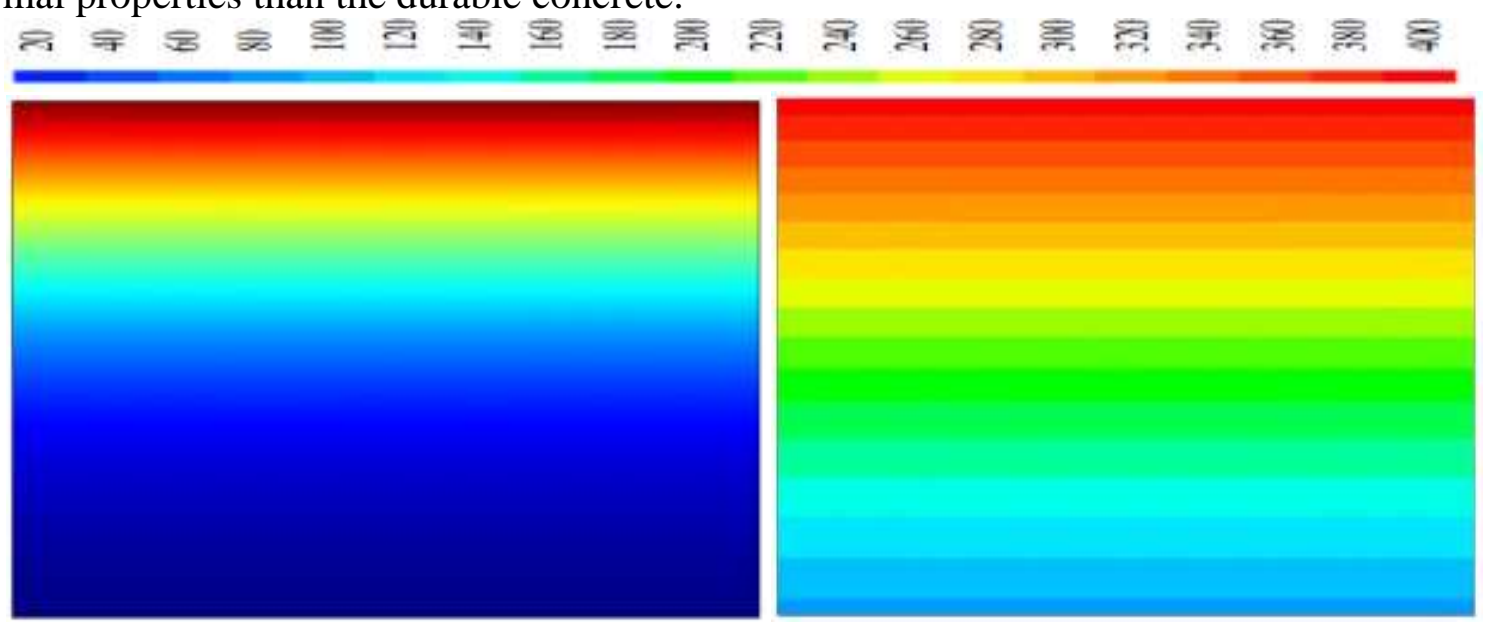

Fig.8.Iso-values of the temperature $\left[{ }^{\circ} \mathrm{C}\right]$ after $300 \mathrm{~min}$ of heating (a) in the polymer concrete and (b) in the cement concrete [29]

Fig. 8 shows the iso-values of the specimen temperature obtained by the macroscopic simulation after 300 minutes of heating. We noticed a significant difference between the iso-values obtained for the two types of 
concretes is found that thermal degradation is more important for cement concrete than for PC samples. Which gives cement concrete a lower thermal resistance than resin concrete.

Fig.9 shows a comparison of the evolution as a function of time of the temperature for a depth $10 \mathrm{~mm}$, of the heated surface, and this by macroscopic simulation for the two types of concretes. It can be seen that for the same position, the cement concrete after 300 min reaches a temperature of $375^{\circ} \mathrm{C}$ while the resin concrete reaches only $225^{\circ} \mathrm{C}$. These results allow us to notice that resin concrete can be considered more resistant to the temperature than cement concrete hence their importance of their use in the field of construction.

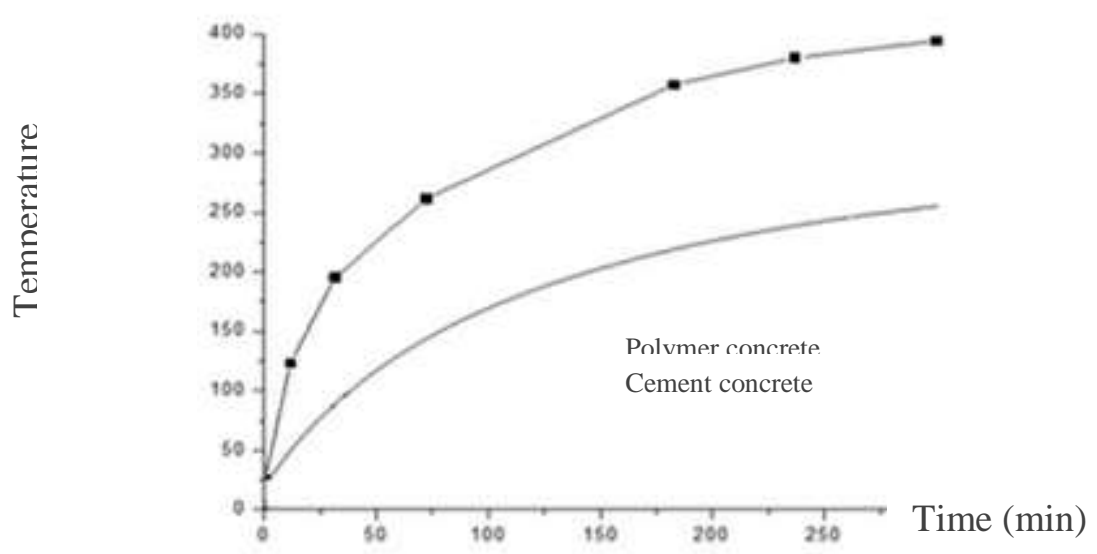

Fig.9. Comparison of heat transfer in resin concrete to that of cement concrete

\section{Evolution Of The Thermal And Mechanical Characteristics Of Resin Concrete \\ 4.1. Evolution of thermal conductivity}

The effect of heating on the thermal conductivity was evaluated. It appears that after exposure to temperature the conductivity have lower due to the temperature increases (Fig.10). Moreover a fall is observed for $\mathrm{T}>150{ }^{\circ} \mathrm{C}$. The measurement of the thermal properties is in accordance and prove that the major thermal degradation of the PC samples is due debonding between the epoxy polymeric matrix and the aggregature. This phenomenon is more significant for $\mathrm{T}>150{ }^{\circ} \mathrm{C}$ and is responsable in the stifness loss of the PC.

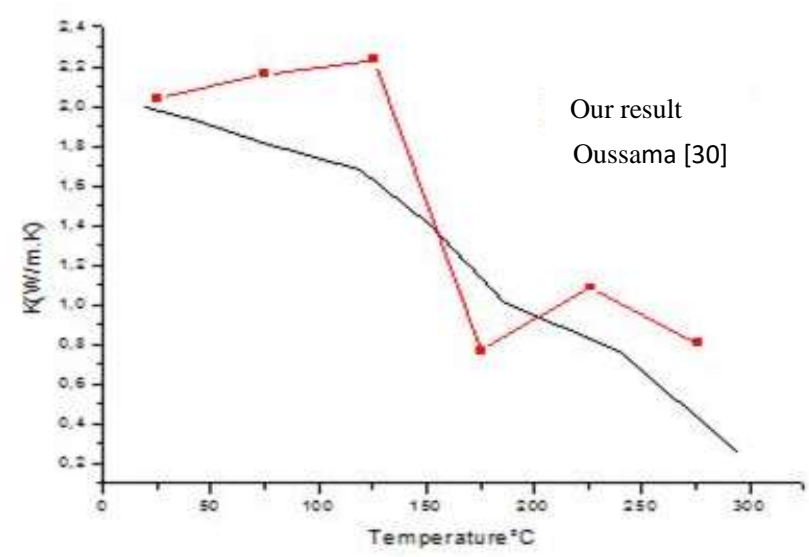

Fig.10. Effect of the exposure temperature on the thermal conductivity of the PC

\subsection{Evolution of the Young's module}

The Young's modulus decrease when the exposure temperature raises (Fig.11). This reduction can be explained by the damage caused by the loss of cohesion between the aggregates and the matrix. Debonding between epoxy binder and aggregates is mainly due the difference of thermal expansion coefficient of both materials. The loss of the polymer concrete stiffness can also be attributed to oxidative thermal degradation of the epoxy binder. 
According to the results of the literature [30- 32] the Young's modulus of a material decreases with temperature. Indeed, the thermal agitation causes a removal of the atoms and causes the decline of the intensity of the interatomic bonds; therefore any elevation (respectively any decrease) of the temperature, is therefore reflected by a significant decrease (respectively growth) in the elastic stiffness of the materials and consequently the Young's modulus.

In addition, it is shown that this variation of the Young's modulus is generally linear in the elastic zone of the material [33]. Our results are therefore in agreement with the experimental data.

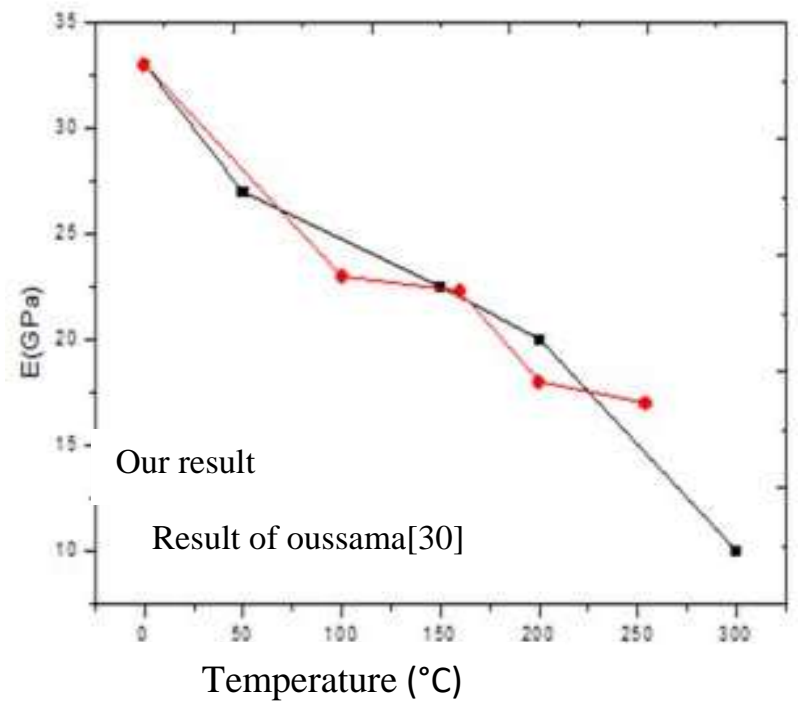

Fig.11. Modulus of elasticity as a function of exposure temperature

\section{Conclusion}

In this paper we have developed a model simulating the thermal and thermomechanical behavior of resin concrete. In the first part we studied the thermal transfer during the infusion process. For the second part, we studied the case of a sample of concrete in compression and bending under high temperature, we have shown that epoxy polymer mortars can be used frequently in structures subjected to high displacement rates and under natural climate. We were able to validate our results with experimental studies of the literature. Similarly, the behavior of high temperature resin concrete with cement concrete was compared. These results allow us to observe that resin concrete can be considered to be more resistant to temperature than cement concrete, hence the importance of their use in the construction field.

\section{References}

1. COMSOL AB. (2007). COMSOL Multiphysics user's guide - V3.4.

2. NOUMOWE A (1998). Effet de hautes températures sur le béton. Cas particulier du béton à hautes performances, Thèse de doctorat INSA Lyon.

3. ANDERBERG Y. (1997), Spalling phenomena of HPC and OC, Proc. Int. Workshop on Fire Performance of High-Strength-Concrete, NIST Spec. Publ. 919, L.T. Phan, N.J. Carino, D. Duthinh, and E. Garboczi, eds., National Institute of Standards and Technology, Gaithersburg, Md., pp.69-73.

4. BAZANT Z.P., Analysis of pore pressure, thermal stresses and fracture in rapidly heated concrete, Int Workshop on Fire Performance of High-Strength Concrete, NIST, Proc.,_ed. par L.T. Phan, N.J. Carino, D. Duthin et E. Garboczi (1997), NIST Special publication 919, National Institute of Standards and Technology, Gaithersburg, Maryland.

5. ULM F.J., ACKER P., LEVY M (1999). Chunnel fire. II: Analysis of concrete damage, Journal of Engineering Mechanics, pp.283-289.

6. GAWIN D., PESAVENTO F. (2003), SCHREFLER B.A., Modelling of hygro-thermal behaviour of concrete at high temperature with thermo-chemical and mechanical material degradation, Comput. Methods Appl. Mech. Engrg., pp. 1731-1771.

7. DAL PONT S (2003). Lien entre la perméabilité et l'endommagement dans les bétons à haute température. Thèse de Doctorat, Ecole Nationale des Ponts et Chaussées, Marne La Vallée, France. 
8. João Marciano Laredo dos Reis (2012), Effect of Temperature on the Mechanical Properties of Polymer Mortars, Materials Research, pp. 645-649.

9. Dimitrienko YI.(1997), Thermomechanical behaviour of composite materials and structures under high temperatures: 1. Materials. Composites Part A: Applied Science and Manufacturing, pp.453461.

10. Tavares CML, Ribeiro MCS, Ferreira AJM and Guedes RJC (2002). Creep behaviour of frpreinforced polymer concrete. Composite Structures, pp.47-51.

11. Ribeiro MCS, Novoa PR, Ferreira AJM and Marques AT (2004). Flexural performance of polyester and epoxy polymer mortars under severe thermal conditions. Cement and Concrete Composites, pp.803-809.

12. Shokrieh MM, Heidari-Rarani M, Shakouri M and Kashizadeh E 2011). Effects of thermal cycles on mechanical properties of an optimized polymer concrete. Construction and Building Materials, pp. 3540-3549.

13. Elalaoui O, Ghorbel E, Mignot V and Ben Ouezdou M. (2012), Mechanical and physical properties of epoxy polymer concrete after exposure to temperatures up to $250{ }^{\circ} \mathrm{C}$. Construction and Building Materials, pp. 415-424.

14. Oshima M, Sato R, Hayashi F and Koyanagi W. (2001), Thermal properties and temperature dependency of mechanical properties of resin concretes for structural use. In: Proceedings of the 10th International Congress on Polymers in Concrete; 2001; Honolulu. Honolulu.

15. H. Abdel-Fattah, M. El-Hawary (1999), Flexural behavior of polymer concrete, Construction and Building Materials, pp. 253-262.

16. M. El-Hawary, H. Abdel-FATTAH (2000), Temperature effect of mechanical behavior of resin concrete, Construction \& building materials, pp.317-323.

17. C.Vipulanandan, N.Dharmarajan (1987), Flexural Behavior of polyester polymer concrete. Concrete and cement research, pp. 219-230.

18. Vipulanandan C., Dharmarajan N., Ching E. (1988), Mechanical behaviour of polymer

19. concrete systems. Materials and Structures, p p. 268-277.

20. J. Mazars.(1984), Application of the mechanics of damage to the nonlinear behavior and fracture of structural concrete, State Doctorate Thesis of Paris VI University.

21. Ulm F.J., Acker P., Levy M.(1999), The Chunnel fire: analysis of concrete damage. Journal of Engineering Mechanics, 125(3), pp.283-289.

22. Loi darcy H. Darcy : Les fontaines publiques de la ville de Dijon. Victor DALMONT

23. Éditeur, 1856.

24. C. Williams, J. Summerscales et S. Grove : Resin infusion under flexible tooling (RIFT): a review. Composites Part A: Applied Science and Manufacturing, 27(7):517-524, 1996.

25. Guillaume PACQUAUT(2010), Stokes / Darcy coupling in a Large Level-set frame deformations for the simulation of elaboration processes by resin infusion, These from the National School of Mines of SaintEtienne

26. P.Wang, J.Molimard, S.Drapier, A.Vautrin, J.C. Minni (2012), Monitoring the resin infusion manufacturing process under industrial environment using distributed sensors. Journal of Composite Material, .

27. Peng WANG (2010), Etude numérique et expérimentale de procédé d'elaboration des matériaux composites par infusion de résine, thèse de l'École Nationale supérieure des Mines de Saint-Étienne.

28. M.M. Shokrieh all. (2011), Effects of thermal cycles on mechanical properties of an optimized polymer concrete, Construction and Building Materials,pp. 3540-3549.

29. João Marciano Laredo dos Reis (2012), Effect of Temperature on the Mechanical Properties of Polymer Mortars, Materials Research, pp. 645-649.

30. S.Chandra,Y.Ohama, 'Classification of concrete-polymer composites", dans Polymers in Concrete,chap.2,CRC Press,p204,1994.

31. Thi Thu Huong LE, Multi-scale study of the thermo-hydro-mechanical behavior of cementitious materials: morphological approach to take into account the mesostructure. Thesis of the University of Paris-East.

32. Oussama ELALAOUI (2012), Optimization of the formulation and the resistance to high temperatures of an epoxy-based concrete, Cotutelle thesis between: Graduate School of Science and 
Engineering University of Tunis El Manar and University of Cergy-Pontoise (France) National School of Engineers of Tunis (Tunisia).

33. Michel, D.(2004), Aide-mémoire science des matériaux, Dunod, Paris, 89-130.

34. Namiko, Y., Guzman, R. V., Wardle, B. L.(2012), Comp. Sci. Tech., pp. 1961-2032.

35. Zhonghao, J., Xianli ; L., Hanzhuo, Z., Guangyue, L., Jianshe, L.(2005), Comp. Sci. Tech.,pp. 11761194. 